\title{
Influence of semiconductor and metal nanoparticles on the dielectric properties of ionic matrix cadmium octanoate
}

\author{
Dmytro Zhulai ${ }^{1}$, Denys Fedorenko ${ }^{1}$, Alexander Kovalchuk², Svetlana Bugaychuk', \\ Gertruda Vasylivna Klimusheva ${ }^{1 *}$ and Tetyana Alfredivna Mirnaya ${ }^{3}$
}

\begin{abstract}
Dielectric properties of ionic composites consisted of cadmium octanoate matrix and semiconductor or metal nanoparticles have been investigated. The nanoparticles of different nature (semiconductor CdS, metal Au, and metal core-semiconductor shell Au-CdS) were chemically synthesized in the smectic A phase of $\left(\mathrm{Cd}^{+2}\left(\mathrm{C}_{7} \mathrm{H}_{15} \mathrm{COO}\right)^{-2}\right.$, $\left(\mathrm{dC}_{8}\right)$ that was used as a nanoreactor. These nanocomposites are very stable and well ordered; the size and shape of the nanoparticles (NPs) are well controlled during the synthesis. The main aim of the research was to examine the influence of nanoparticles on the dielectric properties of ionic matrix, which has smectic A ordered structure. Electrical characteristics were investigated at different temperatures, which correspond to different phases of the material. The conductivity of nanocomposites has an activation nature. The electrical conductivity anisotropy confirms the structural anisotropy of the nanocomposites. The conductivity of the nanocomposite along the cation-anion layers is higher by 2 orders of magnitude than that across the cation-anion layers. Basing on the experimental data, we proposed the simple model of the charge carriage process.
\end{abstract}

Keywords: Ionic liquid crystal; Nanocomposite; Dielectric conductivity; CdS; Au quantum dots

\section{Background}

Researchers pay much attention to develop composite materials, as well as nanocomposites that exhibit new functional features. Usually, addition of nanoparticles (NPs) does not change the matrix ordering but extends the features of the composed material. Thus, this is a possibility to create nanomaterials with desired characteristics.

The new class of ionic liquid crystals based on metal alkanoates possesses a number of unique properties, such as intrinsic ionic conductivity, high solvating power, and ability to form time-stable mesomorphic glasses. The mesophase of metal alkanoates can be used as a nanoreactor for chemical synthesis and stabilization of semiconductor nanoparticles [1-4]. Earlier, electrical conductivity of lyotropic and thermotropic ionic liquid crystals of different metal alkanoate was studied [5]. The high electrical conductivity was recently observed in the potassium caproate

\footnotetext{
* Correspondence: klimush@iop.kiev.ua

${ }^{1}$ Institute of Physics of National Academy of Sciences of Ukraine, Nauky prosp., 46, Kyiv 03028, Ukraine

Full list of author information is available at the end of the article
}

lyotropic ionic liquid crystals (LILC). By applying an electric field, the potassium cations can easily migrate along the cation-anion layers, which contain water molecules. Thus, the conductivity along the cation-anion layers appears to be higher than that in the isotropic water electrolytes [6]. The anisotropy of the electrical conductivity in the mesophase of cobalt decanoate is as high as 4 orders of magnitude due to the alignment of the thermotropic smectic A phase.

In the present work, we investigate the electrical properties of pure cadmium octanoate matrix, as well as cadmium octanoate composites with different concentration of semiconductor, metal, or metal core-semiconductor shell nanoparticles. The main goal of the investigation is to get the material with extended electrical properties and propose the applications for these nanocomposites.

\section{Methods}

Cadmium octanoate $\left(\mathrm{Cd}^{+2}\left(\mathrm{C}_{7} \mathrm{H}_{15} \mathrm{COO}\right)^{-2}, \mathrm{CdC}_{8}\right)$ exists in the form of the polycrystalline powder at room temperature. Within the temperature range $98^{\circ} \mathrm{C}$ to $180^{\circ} \mathrm{C}$, 

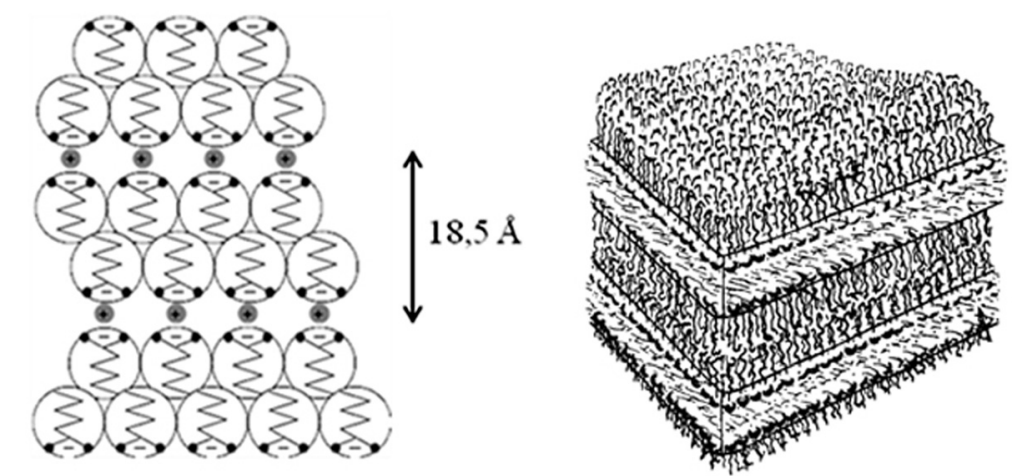

Figure 1 Model of layered structure (smectic $A$ ) of cadmium octanoate $\mathrm{CdC}_{8}$.

cadmium octanoate gets liquid, forming the smectic A mesophase (Figure 1), which can be used for chemical synthesis of semiconductor NPs [7]. The liquid crystalline smectic A structure of $\mathrm{CdC}_{8}$ can be frozen by quick cooling back to the room temperature.

We study cadmium octanoate composites containing nanoparticles of different nature. The semiconductor NPs were presented by $\mathrm{CdS}$, metal $\mathrm{Au}$, and metal coresemiconductor shell Au-CdS. All NPs were synthesized directly in the $\mathrm{CdC}_{8}$ matrix by the template-controlled method: a cadmium octanoate polycrystalline powder impregnated with a saturated aqueous-alcoholic solution of thiourea was put in a furnace at $150^{\circ} \mathrm{C}$ (the temperature of the mesophase of cadmium alkanoates) in argon atmosphere for $1 \mathrm{~h}$. In such conditions, NPs grow in the matrix. After the synthesis, the mesophase of the composite was cooled down to room temperature. In such way, the polycrystalline powders of the nanocomposites were obtained. The presence of the NPs inside could be simply confirmed by the changes in optical absorbance spectrum. Also, the size of the NPs could be estimated by these spectra. Thus, the nanocomposites containing semiconductor CdS NPs, metal Au NPs, and metal core-semiconductor shell Au-CdS NPs were obtained.

It has been shown that the increase of the concentration of sulfide ions in the matrix does not affect the size of the NPs but increases their concentration in the matrix. Thus, the varying of the starting concentrations of thiourea allows to obtain the nanocomposites with the different concentrations of NPs. In our case, the composites with semiconductor nanoparticles used were 2, 4, and $6 \mathrm{~mol} \% \mathrm{CdS}$, for the composites with metals were 2 and $4 \mathrm{~mol} \% \mathrm{Au}$, and for the composites with core-semiconductor shell were $4 \mathrm{~mol} \% \mathrm{Au}+$ 2 mol\% CdS.

$\mathrm{X}$-ray measurements allowed to estimate the diameters of synthesized NPs. They appeared to be: semiconductor
$\mathrm{CdS} \approx 2.5 \mathrm{~nm}$, metal $\mathrm{Au} \approx 20 \mathrm{~nm}$, and metal coresemiconductor shell $\mathrm{Au}-\mathrm{CdS} \mathrm{NPs} \approx 22.5 \mathrm{~nm}$. Also, the results show that the NPs have a small dispersion in their sizes; their shape is spherical.

The nanocomposites are stable over a long time (years) and ordered in a layered matrix (see Figure 2) [8].

For electrical conductivity measurements, the nanocomposites were placed in flat cells with nickel electrodes and glass supports. Two geometric configurations of cells (with different location of the electrodes) were used to investigate the anisotropy of the conductivity; see Figure 3. We placed the electrodes in a plane of glass substrates to direct the electric current across (Figure 3a) the ionic layers of the nanocomposite. To direct the current along the ionic layers, the electrodes were located on the sides of the material area (Figure 3b). The spacers in the case (3a) adjusted the thicknesses of the samples. In the case (3b), the thickness is given by the thickness of the electrodes. The thicknesses of samples are chosen to be $30 \mu \mathrm{m}$ in the case (3a) and $1 \mathrm{~mm}$ for the case (3b).

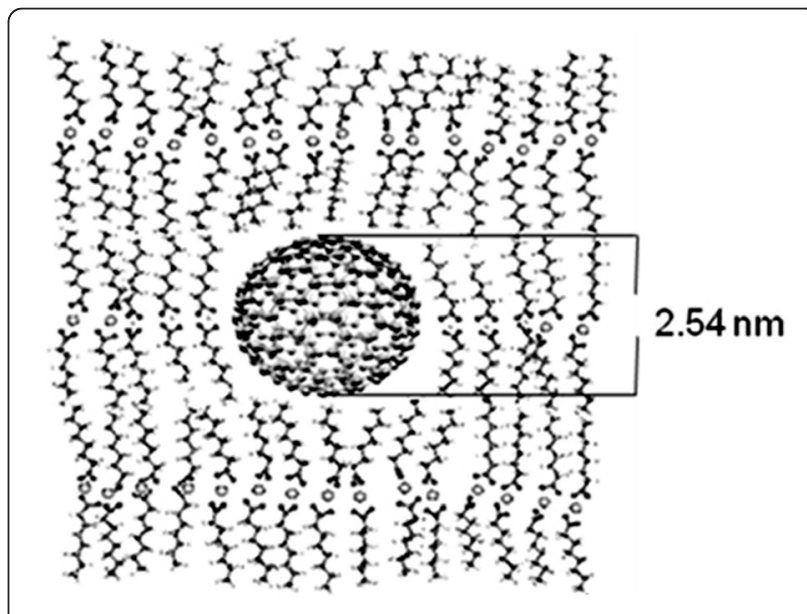

Figure 2 Model of semiconductor CdS NPs in a CdC8 matrix. 


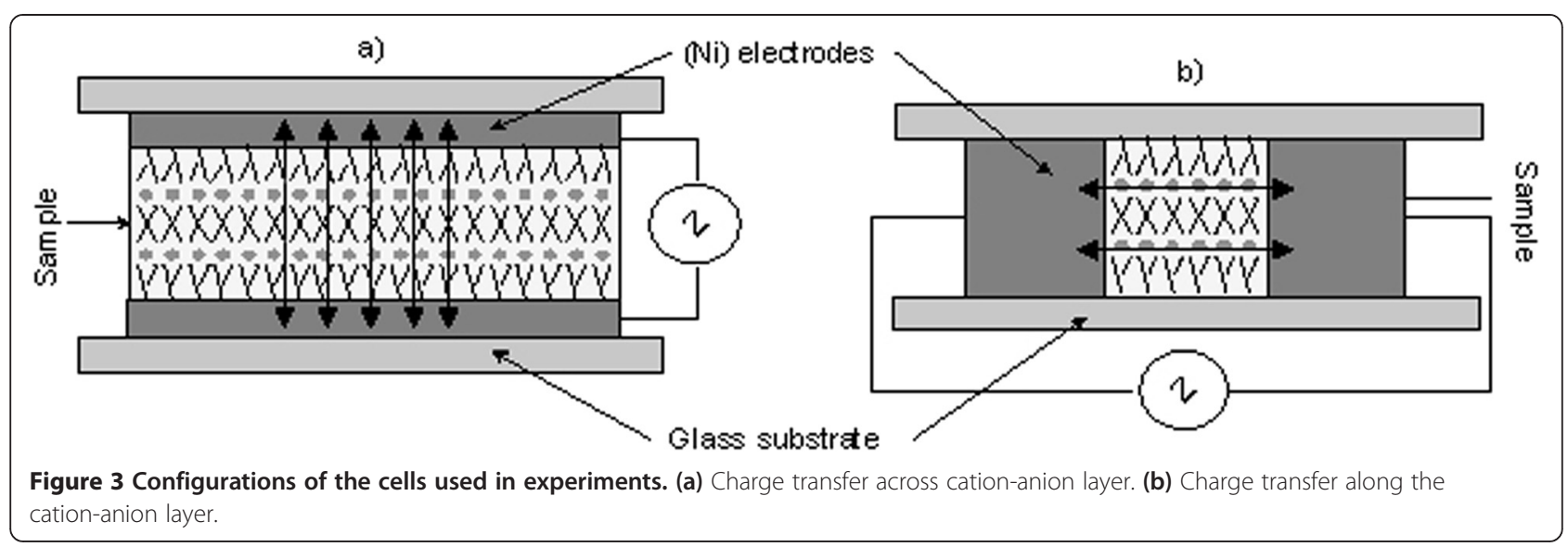

The electric conductivity is measured using the oscilloscopic technique $[9,10]$. A voltage signal has a triangular shape with the peak amplitude $0.25 \mathrm{~V}$. The signal frequency was changed within the range from 50 to $10^{6} \mathrm{~Hz}$. It was found that the resistance of the samples has no dispersion at frequencies above $5 \times 10^{3} \mathrm{~Hz}$, since the frequency $10^{4} \mathrm{~Hz}$ was selected to measure the electrical conductivity.

In our experiments, we measured the volumetric resistance directly. Thus, the geometric parameter, $k$, must be involved in consideration for each sample. Then, the conductivity is estimated as $\sigma=k / R$. The geometric parameter $k=l /(d \cdot z)$ depends on the sample thickness $d$, the length of the metal electrode $z$, and the distance between electrodes $l$.

To make the temperature measurements available, the samples were placed into a thermostat. The temperature inside could be adjusted in range from $20^{\circ} \mathrm{C}$ to $150^{\circ} \mathrm{C}$, with accuracy of $1^{\circ} \mathrm{C}$.

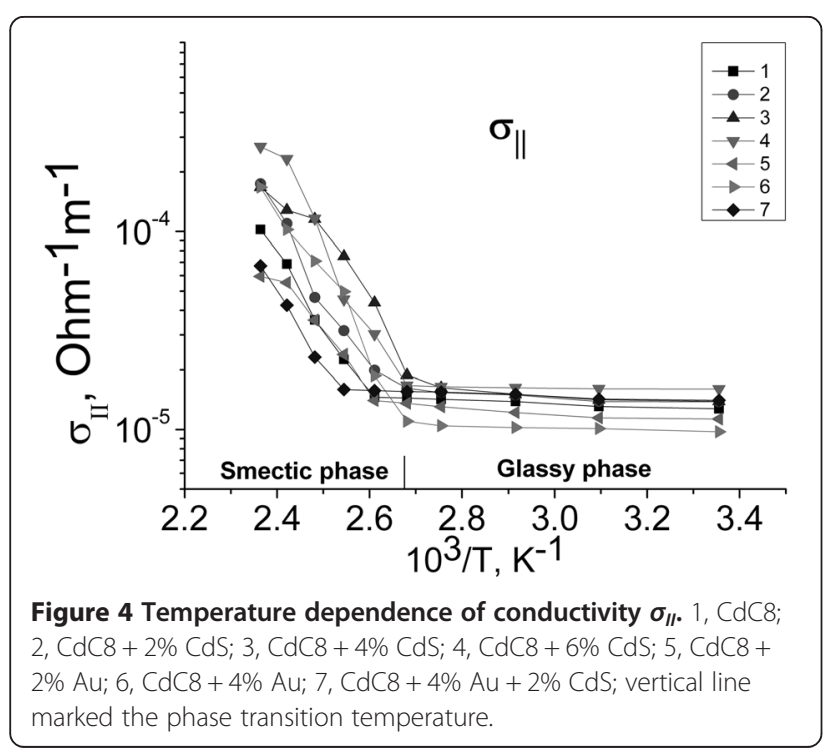

\section{Results and discussion}

The electrical conductivity along cation-anion layers $\left(\sigma_{I I}\right.$; Figure 4$)$ and across them $\left(\sigma_{\perp}\right.$; Figure 5$)$ was measured in samples with different concentrations of nanoparticles. We used the following concentrations: semiconductor $\mathrm{CdS}$ were 2, 4, and $6 \mathrm{~mol} \%$, metal Au 2 and $4 \mathrm{~mol} \%$, and metal core-semiconductor shell $4 \mathrm{~mol} \%$ $\mathrm{Au}+2 \mathrm{~mol} \% \mathrm{CdS}$. The temperature was changed in range from a room temperature up to $150^{\circ} \mathrm{C}$. The results are shown in Figure 4. It is clearly seen that the conductivity is a bit larger in the samples with the larger concentration of the NPs. Also, the conductivity along the cation-anion layers is by 2 orders of magnitude higher than that across them.

Comparison of the values of dependences $\sigma_{I I}(1 / T)$ at Figure 4 and $\sigma_{\perp}(1 / T)$ at Figure 5 confirms the anisotropy of our materials. The difference in 2 orders of magnitude arises from the large difference in mobility of the charge carriers along and across of the matrix cation-anion

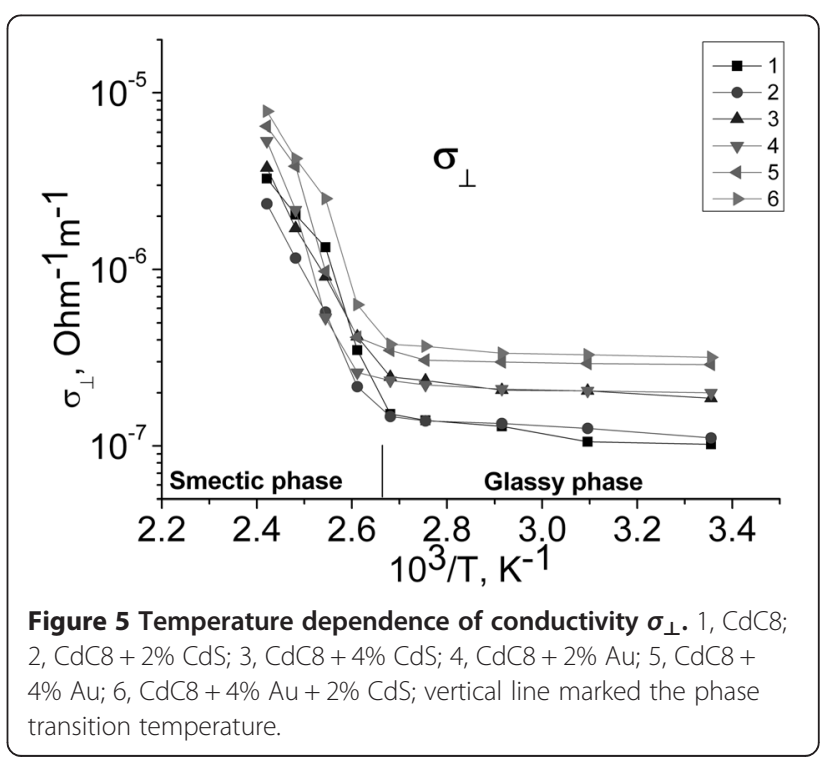


Table 1 Activation energy of conductivity on the concentration NPs in glassy phase of nanocomposites along and across cation-anion layers

\begin{tabular}{llllllll}
\hline Concentration of NPs in samples & Pure CdC8 & $\mathbf{2 \% ~ C d S}$ & $\mathbf{4 \% ~ C d S}$ & $\mathbf{6 \%}$ CdS & $\mathbf{2 \% ~ A u}$ & $\mathbf{4 \% ~ A u}$ & $\mathbf{4 \% ~ A u + 2 \% ~ C d S}$ \\
\hline $\mathrm{E} \|, e V$ & 0.017 & 0.015 & 0.013 & 0.003 & 0.33 & 0.16 & 0.009 \\
$\mathrm{E} \perp, \mathrm{eV}$ & 0.04 & 0.027 & 0.023 & & 0.16 & 0.1 & 0.18 \\
\hline
\end{tabular}

layers. Dependencies $\sigma_{I I}(1 / T)$ and $\sigma_{\perp}(1 / T)$ can be approximated by two straight lines each, since the activation energy $E_{a}$ can be established for both phases and for each concentration of the nanoparticles using the formula (1).

At the temperatures of the mesophase existence, the dependence of $\sigma(\mathrm{T})$ can be approximated by straight lines in Arrhenius coordinates $\ln \sigma(1 / T)$. Therefore, the conductivity of nanocomposites has an activation character and can be described by the Arrhenius formula:

$$
\sigma=\sigma_{0} \exp \left(-\frac{E a}{k_{B}} T\right)
$$

where $\sigma_{0}$ is the parameter, which depends on the phase of the composite, $E_{a}$ is the activation energy of conductivity, and $k_{B}$ is the Boltzmann constant. Thus, we can determine the activation energy of conductivity both for different nanocomposite phases and for different design of the cells.

Dependence of the $E_{a}$ of composites on concentration of CdS nanoparticles and Au nanoparticles at the temperature corresponding to the glassy phas

Let us consider the glassy phase first. The activation energy $E_{a}$ decreases with the concentration of NPs in both directions of the charge transport (along and across to the cation-anion layers). The reason of the small values of the activation energy in the glassy phase points out that the main charge is transported by electrons (Table 1 ).

Dependence of the $E_{a}$ of composites on the concentration of CdS nanoparticles and Au nanoparticles at temperature smectic phase existence

The conductivity along the cation-anion layers significantly grows at temperatures above $100^{\circ} \mathrm{C}$ when the glassy nanocomposite turns to the smectic A phase. The activation energy increases with the concentration of both semiconductor and metal NPs. In samples of nanocomposites with $\mathrm{CdS}$ nanoparticles, $E_{\text {aII }}$ grows from $0.78 \mathrm{eV}$ for the pure matrix to $1.24 \mathrm{eV}$ for the nanocomposite with $6 \%$
CdS. In samples of nanocomposites with gold NPs, $E_{a I I}=$ $0.61 \mathrm{eV}$ for $2 \% \mathrm{Au}$ NPs and $E_{a I I}=0.81 \mathrm{eV}$ for $4 \% \mathrm{Au}$ NPs. This may be due to the formation of additional charge trapping centers.

In contrary with previous case, the conductivity across the cation-anion layers decreases with the concentration of the NPs. In samples of nanocomposites with $\mathrm{CdS}$ nanoparticles, $E_{a \perp}$ decreases from $1.58 \mathrm{eV}$ for the pure matrix to $0.84 \mathrm{eV}$ for the nanocomposite with $4 \% \mathrm{CdS}$. This result can be explained if we imagine that the charge that is traveling across the cation-anion layers of matrix is pushed between molecules of alkanoate chain. Then, the increase of the NPs concentration increases the number of 'defects' in close packed molecules of the CdC8 matrix. Thus, the mobility of the carriers gets higher with the increase of the number of areas where the close package of the alkanoate chains is deformed. Thus, the higher concentrations of NPs provide higher mobility of the cadmium cations across the cation anion layers.

For samples containing core-shell NPs of $\mathrm{Au}+\mathrm{CdS}$, $E_{a}=0.66 \mathrm{eV}$ (Table 2).

Dependence of the anisotropy of the conductivity on the concentration of $\mathrm{CdS}$ and Au nanoparticles

The anisotropy of conductivity in the smectic phase of the nanocomposites is smaller than that in the glassy state. With an increase of the NPs concentration, the conductivity anisotropy increases for the smectic phase and decreases for the glassy phase. This once again proves that the $\mathrm{CdS}$ and Au NPs affect the ionic conductivity in both phases of the nanocomposite in a different way (Figures 6 and 7) (Table 3).

Dielectric properties of pure matrix $\mathrm{CdC}_{8}$ on the temperature in a range, where there is no dispersion at frequencies $20 \mathrm{kHz}$, have been studied. The frequency $20 \mathrm{kHz}$ was selected to ensure the absence of dispersion. While the temperature is far from the phase transition and the dielectric permittivity, the glassy state is not depending on the temperatures. It's value is about

Table 2 Activation energy of conductivity for smectic A phase on the concentration of NPs along and across cation-anion layers

\begin{tabular}{|c|c|c|c|c|c|c|c|}
\hline & Pure CdC8 & $2 \% \mathrm{CdS}$ & $4 \% \mathrm{CdS}$ & $6 \% \mathrm{CdS}$ & $2 \% \mathrm{Au}$ & $4 \% \mathrm{Au}$ & $4 \% A u+2 \% C d S$ \\
\hline $\mathrm{E} \|, \mathrm{eV}$ & 0.78 & 0.8 & 0.93 & 1.24 & 0.61 & 0.81 & 0.66 \\
\hline $\mathrm{E} \perp, \mathrm{eV}$ & 1.58 & 1.12 & 0.84 & & 1.35 & 1.37 & 1.35 \\
\hline
\end{tabular}




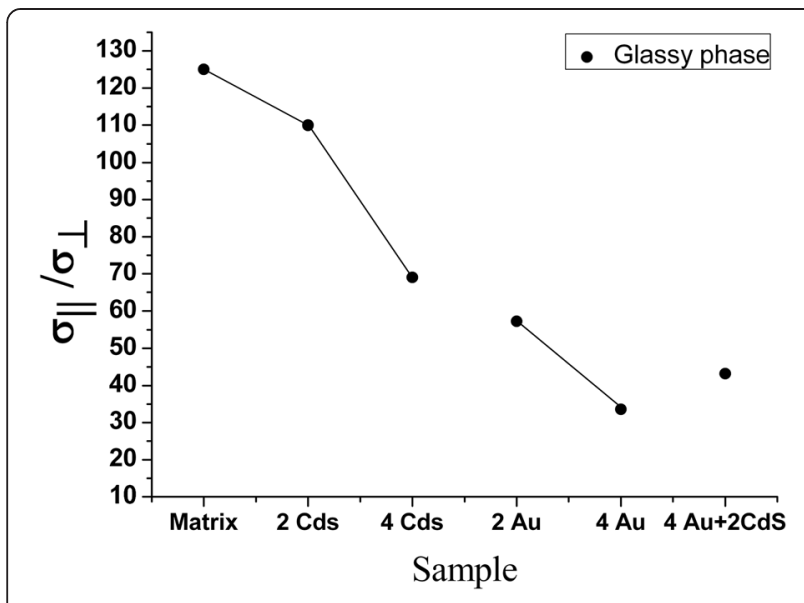

Figure 6 Dependence of the anisotropy of the conductivity on the concentration of $\mathrm{CdS}$ and Au nanoparticles in glassy phase.

37 units. With the increase of the temperature up to $100^{\circ} \mathrm{C}$ (the phase transition from the glassy phase into the smectic phase is $98^{\circ} \mathrm{C}$ ), we observe the increase of the dielectric permittivity up to 42 units which is very unusual. At higher temperatures, when the material completely got into the smectic phase, the dielectric permittivity decreases again, which is in a complete agreement with the theoretical predictions. The increase of the dielectric permittivity at the temperature close to the phase transition (Figure 8) needs further investigations.

\section{Conclusions}

In general, we can conclude that the nanocomposites based on metal alkanoates with synthesized $\mathrm{CdS}, \mathrm{Au}$, and $\mathrm{Au}+\mathrm{CdS}$ nanoparticles have very interesting electrical properties and are promising for applications in

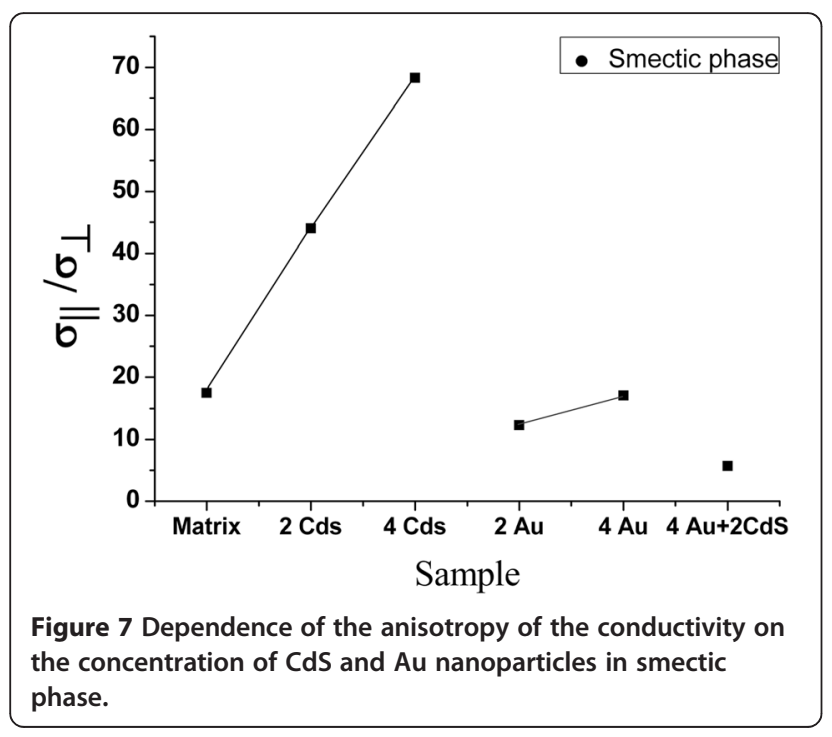

Table 3 Dependence of the anisotropy of the conductivity on the concentration of $\mathrm{CdS}$ and $\mathrm{Au}$ nanoparticles

\begin{tabular}{lllllll}
\hline $\begin{array}{l}\text { Concentration } \\
\text { of NPs in } \\
\text { samples }\end{array}$ & $\begin{array}{l}\text { Pure } \\
\text { CdC8 }\end{array}$ & $\begin{array}{l}\mathbf{2 \%} \\
\text { CdS }\end{array}$ & $\begin{array}{l}\mathbf{4 \%} \\
\text { CdS }\end{array}$ & $\begin{array}{l}\mathbf{2 \%} \\
\mathrm{Au}\end{array}$ & $\begin{array}{l}\mathbf{4 \%} \\
\mathrm{Au}\end{array}$ & $\begin{array}{l}\mathbf{4 \%} \mathrm{Au}+ \\
\mathbf{2 \%} \mathrm{CdS}\end{array}$ \\
\hline $\mathrm{AG}$ & 17.5 & 44 & 68.3 & 12.3 & 17.1 & 5.7 \\
$\mathrm{AS}$ & 125 & 110 & 69 & 57.3 & 33.6 & 43.2 \\
\hline
\end{tabular}

$A_{G}$, anisotropy of the conductivity for the glassy phase; $A_{S}$, anisotropy of the conductivity for the smectic phase.

optoelectronics. Most important results and conclusions are the following:

- The conductivity of nanocomposites has an activating dependence in both glassy and smectic A phases.

- The conductivity of the nanocomposite along the cation-anion layers is in 2 orders of magnitude higher than across the cation-anion layers, confirming the structural anisotropy of the nanocomposite in the different phases of the materials.

- Electrons are the main charge carriers in the glassy phase. The increase of the NPs concentration brings additional free charge carriers or increases mobility of carriers.

- In the smectic phase, the increase of the nanoparticle concentration brings additional traps for the carriers, which travel in plane of the cation-anion layers. On the other hand, the nanoparticles deform the alkanoate chains and increase the mobility of the carriers traveling across the layers.

- With the increase of the concentration of $\mathrm{CdS}$ and Au nanoparticles, the anisotropy of the conductivity increases for the smectic phase and decreases for the glassy phase.

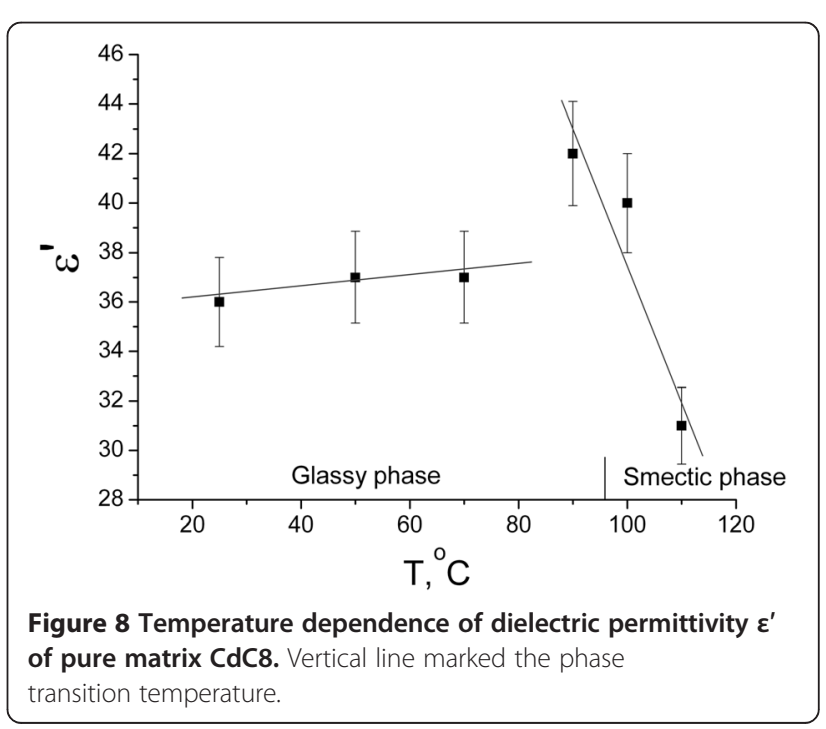


- The temperature dependence of the dielectric permittivity of pure matrix $\mathrm{CdC} 8$ is very unusual and needs to be explored more. It is found that the dielectric permittivity increases at the temperatures close to the glass-liquid crystal phase transition. Such permittivity increase is not typical for ordinary glasses and needs additional investigations.

\section{Competing interests}

The authors declare that they have no competing interests.

\section{Authors' contributions}

MTA synthesized the CdS nanoparticles in cadmium octanoate matrix. KGV carried out the preparation of the samples. ZD and KA made measurement of dielectric properties of ionic matrix cadmium octanoate with semiconductor and metal nanoparticles. KGV, BS, and FD did the in-depth analysis and drafted this manuscript. All authors read and approved the final manuscript.

\section{Acknowledgements}

The work has been funded in part by the projects of the state target scientific and technical program 'Nanotechnologies and Nanomaterials' for 2010 to 2014 (no. 1.1.3.11, 3.5.5.23).

\section{Author details}

${ }^{1}$ Institute of Physics of National Academy of Sciences of Ukraine, Nauky prosp., 46, Kyiv 03028, Ukraine. ${ }^{2}$ National University of Technologies and Design, Nemirovich-Danchenko 2, Kyiv 01011, Ukraine. ${ }^{3}$ V. I. Vernadsky Institute of General and Inorganic Chemistry of National Academy of Sciences of Ukraine, Academician Paladin prosp., 32-34, Kyiv 03142, Ukraine.

Received: 23 October 2014 Accepted: 29 December 2014

Published online: 13 February 2015

\section{References}

1. Asaula VM, Mirnaya TA, Yaremchuk GG, Ponamorenko OA, Volkov SV. Feature of the synthesis nanoparticles in ionic crystal medium. Ukr Chem J. 2010;76(5):20-5.

2. VM Asaula, TA Mirnaya, GG Yaremchuk, SV Volkov. Method for Producing a Liquid Crystal Glassy Nanocomposite Materials with Semiconductor Nanoparticles of Metal Sulfides. - Patent for utility model number 58 140, Ukraine, u 201003708 IPC (2011.01) C01G11/00, C01G9/00, C01G21/00, B82B1/00, announced 31.03.2010, published 11.04.2011, Bull. №7, 2011.

3. TA Mirnaya, GG Yaremchuk, VM Asaula, NA Leonova, SV Volkov. Method for Producing Gold Nanoparticles in The Liquid Crystal Caprylate Matrix. Patent for Utility Model Number 86660, Ukraine, u 201307606 IPC (2013.01) C01G7/00, B82B1/00, announced 17.16.2013, published 10.01.2014, Bull. №1, 2012.

4. Mirnaya TA, Volkov SV. Ionic Liquid Crystals as Universal Matrices (solvents): Main Criteria for lonic Mesogenicity. In: Rogers RD, Seddon KR, Volkov SV, editors. Green Industrial Applications of Ionic Liquids. London: Kluwer Academic Publishers; 2002

5. Garbovskiy Y, Kovalchuk AV, Grydyakina A, Bugaychu SA, Mirnaya T, Klimusheva GV. Electrical conductivity of lyotropic and thermotropic ionic liquid crystals consisting of metal alkanoates. Liq Cryst. 2007;34(5):599-603.

6. DR Lide. Handbook of Chemistry and Physics 84th Edn, CRC Press (2003-2004).

7. Mirnaya TA, Asaula VN, Volkov SV, Tolochko AS, Melnik DA, Klimusheva GV. Synthesis and optical properties of liquid crystalline nanocomposites of cadmium octanoate with CdS quantum dots. Phys Chem Solid State. 2012;13(1):131-5.

8. Klimusheva GV, Dmitruk I, Mirnaya T, Tolochko A, Bugaychuk SA, Naumenko $A$, et al. Monodispersity and ordering of semiconductor quantum dots synthesized in ionic liquid crystalline phase of cadmium alkanoates. Liq Cryst. 2013;40(7):980-8.

9. Twarowski FJ, Albrecht AC. J Chem Phys. 1979;70(n5):2255-61.

10. Kovalchuk AV. Ukr Phys J. 1996:41:991-8.

\section{Submit your manuscript to a SpringerOpen ${ }^{\odot}$ journal and benefit from:}

- Convenient online submission

Rigorous peer review

- Immediate publication on acceptance

- Open access: articles freely available online

- High visibility within the field

- Retaining the copyright to your article

Submit your next manuscript at $>$ springeropen.com 